\title{
Erratum to: The devil lies in the definition: competing approaches to fossil fuel subsidies at the IMF and the OECD
}

\author{
Jakob Skovgaard ${ }^{1}$
}

Published online: 1 June 2017

(C) Springer Science+Business Media Dordrecht 2017

\section{Erratum to: Int Environ Agreements DOI 10.1007/s10784-017-9355-z}

The original article was published without acknowledgements and funding information. The complete acknowledgements section is given in this erratum.

Acknowledgements An earlier version of this paper was presented at the workshop "Energy subsidies at the intersection of the climate, energy and trade regimes". The author would particularly like to thank Harro van Asselt, Thijs Van de Graaf, Sebastian Oberthür, the two anonymous reviewers and the participants in the above-mentioned workshop for their extremely useful comments and suggestions at the various stages of writing and revising this paper.

Funding The research for this article was undertaken as part of the project "International Economic Institutions and Domestic Actors in the Climate Regime Complex", which has been funded by the Swedish Research Council [Vetenskapsrådet], the Bank of Sweden Tercentenary Foundation [Riksbankens Jubileumsfond], and the Swedish Research Council Formas [Forskningsrådet Formas].

The online version of the original article can be found under doi:10.1007/s10784-017-9355-z.

Jakob Skovgaard

jakob.skovgaard@svet.lu.se

1 Department of Political Science, Lund University, P.O. Box 52, 22100 Lund, Sweden 